\title{
Quantitative uncertainty analysis of gravity disturbance. The case of the Geneva Basin (Switzerland)
}

\author{
Lorenzo Perozzi $^{a, *}$, Luca Guglielmetti ${ }^{a}$ and Andrea Moscariello ${ }^{a}$ \\ ${ }^{a}$ Department of Earth Science, University of Geneva, 1205 Geneva
}

\section{ARTICLE INFO}

\section{Keywords:}

Gravity Disturbance

Topographic correction

Uncertainty quantification

Sequential Gaussian Simulation

\begin{abstract}
A B S T R A C T
Gravity data from the International Gravimetric Bureau and the Gravimetric Atlas of Switzerland have been used to evaluate their application and limitations as a subsurface investigation tool to constrain key geological structures in support of the georesources exploration in the Geneva Basin (GB). In this context, the application of an effective processing workflow able to produce a topography-free gravity disturbance and quantify its uncertainty is a crucial first step to delineate gravitational effects correlated to geologic sources of geothermal interest. This study focuses on an innovative processing workflow applied to publicly available gravity data in order to produce stochastic realizations of residuals of the topography-free gravity disturbance. The resulting realizations are compared to a standard interpolation technique, demonstrating the potential of the stochastic approach for georesources exploration in sedimentary basins.
\end{abstract}

\section{Disclaimer}

This is a pre-copyedited, author-produced PDF of an article published in Journal of Applied Geophysics following peer review. It is available from EarthArXiv at https://doi.org/10.31223/X52P5T. The version of record "Perozzi, L., Guglielmetti, L., and Moscariello, A. (2021). Quantitative uncertainty analysis of gravity disturbance. The case of the Geneva Basin (Switzerland). Journal of Applied Geophysics, 193, 104431" is available online at https://doi.org/10.1016/j.jappgeo.2021.104431.

\section{Introduction}

The deployment of renewable energy sources for both power and heat production is accelerating in Switzerland, a trend that will continue thanks to the 2050 Swiss Energy Strategy (SFOE, 2018) that aims at gradually phasing out nuclear power by reducing the energy consumption and increasing heat and electric power generation from renewable energy sources. Geothermal energy will be, therefore, an important resource to supply heat and power for industrial, agricultural, and domestic use.

Increased energy demand, together with the political vision of reducing the use of fossil fuels for heat production in the Canton of Geneva, triggered the development of medium to long-term activities under the umbrella of the GEothermies program (Moscariello, 2019). This program aims to identify potential geological targets at shallow/medium $(0.5$ $\mathrm{km}$ to $3 \mathrm{~km})$ to large depth $(>3 \mathrm{~km})$ to combine heat, power production and potentially mineral extraction.

The Geneva Basin (GB) has been intensively explored for hydrocarbon exploration since the 1960s and for geothermal exploitation in the 1990s, but only non-economically viable production of geo-resources has been recorded. The Thônex-01 well (Jenny et al., 1995), drilled for geothermal heat production, was not commercially productive despite the favourable bottom hole temperature of $88^{\circ} \mathrm{C}$ at $2530 \mathrm{~m}$. However, the geothermal well GEo-01, drilled in 2018 , proved to be successful with a discharge of $50 \mathrm{l} / \mathrm{s}$ of geothermal water at $34^{\circ} \mathrm{C}$ from the upper Mesozoic units (i.e., Lower Cretaceous and Upper Jurassic) and an 8 bars wellhead pressure (Guglielmetti et al., 2020; Moscariello et al., 2020).

The geothermal conditions in the Geneva area have been reconstructed by thermal modeling (Chelle-Michou et al., 2017) and geochemical data (Guglielmetti et al., 2020) revealing a geothermal gradient in the area ranging from $25^{\circ} \mathrm{C} / \mathrm{km}$ to $30^{\circ} \mathrm{C} / \mathrm{km}$. Such a gradient predicts a temperature up to $150^{\circ} \mathrm{C}$ at the top of the basement in the southern part of the Geneva area. Technically and economically extractable geothermal resources are found at many depths in

\footnotetext{
*Corresponding author

@ lorenzo.perozzi@unige.ch (L. Perozzi)

ORCID(s): 0000-0003-4556-1613 (L. Perozzi); 0000-0002-7208-5715 (L. Guglielmetti); 0000-0003-3698-0162 (A. Moscariello)
} 
the Geneva area. At only few tens of meters in the Quaternary deposits, the potential for low enthalpy ground-source heat pump installations is already broadly exploited. From a depth of $0.5 \mathrm{~km}$ to $3 \mathrm{~km}$ the porous Cenozoic Molasse and fractured Mesozoic sequence offers possibilities for both heat extraction and storage (GeoMol Team, 2015) . At $4 \mathrm{~km}$ to $5 \mathrm{~km}$ the Triassic carbonates, the Permo-Carboniferous (PC) sediments, and the crystalline basement have potential for cogeneration of power, heat, and metal extraction.

The identification and characterization of these geological structures before drilling are crucial to target potential geothermal reservoirs. The geophysical method that has demonstrated the best results in many geothermal contexts is $2 \mathrm{D}$ seismic. This is true both in sedimentary basins such as the Bavarian region (Lüschen et al., 2014), Eastern Switzerland (Heuberger et al., 2016). Seismic 2D was mostly acquired in the Geneva Basin (GB) in the 1980s to the 1990s for hydrocarbon exploration (Clerc et al., 2015; Moscariello, 2019) but shows some limitations in delineating shallow Quaternary deposits and deep geologic structures such as the Permo-Carboniferous (PC) grabens which can be associated with lateral density contrast with respect to the surrounding geologic formations. Gravity can therefore contribute to reducing such limitations, this being a standard geophysical subsurface exploration technique in different geological settings (Blakely, 1995; Reynolds, 2011), commonly applied in the early stages of geothermal exploration programs to identify regions of potential interest (Uwiduhaye et al., 2018; Guglielmetti et al., 2013) and for monitoring production operations (Portier et al., 2018).

In the framework of a continued desire to improve the understanding of the subsurface in the GB and reduce the uncertainty related to its petrophysical properties, the aim of this study is to assess the value of existing gravity data. This is achieved through an innovative processing workflow to obtain reliable stochastic realizations of gravity disturbance within the geothermal horizon targets, which allow quantifying gravity disturbance uncertainty and to better correlate gravitational effects to geologic sources of geothermal interest.

\section{Geological setting}

The GB is the westernmost part of the North Alpine Foreland Basin that extends from the Savoy region in France to Linz in the Austrian area. The GB covers about $2000 \mathrm{~km}^{2}$ from the town of Nyon to the NE, down to Vuache Mountain to the SW and it is limited by the Jura Haute-Chaine to the NW and by the subalpine nappes to the SE as shown in Fig. 1 (Kempf and Pfiffner, 2004; Mazurek et al., 2006). The basin originated as a lithospheric flexure response to the topographic load of the Alpine orogeny (Pfiffner et al., 2002) which crustal structure in the study area can be described as a gently dipping surface towards the Alpine orogen with increasing thickness from an average of $20 \mathrm{~km}$ to $30 \mathrm{~km}$ in the Molasse Basin to $40 \mathrm{~km}$ to $50 \mathrm{~km}$ in the high topographic region of the Alpine orogen and to $50 \mathrm{~km}$ to $60 \mathrm{~km}$ south of the Pennidic front.

In the GB four major lithostratigraphic units are recorded at depth (Jenny et al., 1995; Rusillon, 2018; Brentini, 2018; Moscariello, 2019). From bottom to top, these are 1) the crystalline basement including PC troughs at the bottom and its sedimentary cover composed respectively of 2) Mesozoic carbonate units and, at the top, 3) Cenozoic and 4) Quaternary sediments. These units can be approximated to a so-called layer-cake model with sub-parallel formations gently plunging towards SE with an average dip of 3 degrees (Fig. 1).

The crystalline basement is only exposed in the Alps, to the South of the GB, and has been drilled in the study area only by a limited number of wells Rusillon (2018). In the GB and, more generally, across the entire Molasse Basin, the basement is often affected by SW-NE oriented tectonic depressions originated as pull-apart basins during Carboniferous (McCann et al., 2006). These pull-apart structures were further developed during Permian in a wrench faulting regime with syntectonic sedimentation filling them with several thousand meters of deposits (Ziegler, 1990). In the Geneva Basin, Permo-Carboniferous (PC) grabens have been mapped using reflection seismic data (Moscariello et al., 2014); this reveals a set of structures located below the Bornes Plateau, at the northern side of the Saleve ridge and the Jura foothills. The Mesozoic sequence consists, at its base, of Triassic units formed by siliciclastic (Buntsandstein), dolomitic, evaporitic (Mushelkalk), and alternations of evaporitic and dolomitic to marno-dolomitic sequence (Rhetian) that can reach up to $500 \mathrm{~m}$ in thickness. The Jurassic is mostly composed of competent, often massive, carbonate deposits, intercalated with marls (Dogger), and towards the upper part (Malm) this interval locally shows enhanced porosity values thanks to the presence of biothermal reef facies (base Malm) and to fault corridors that cut through sectors of the GB. The Lower Cretaceous, represents the top of the Mesozoic sequence in the GB subsurface and is composed of fine-grained limestones makes it an important geothermal target in the GB. In fact, it can be intensely fractured as shown by the drilling results of the GEo- 01 well, where more than $70 \%$ of the total flow rate is discharged from the Cretaceous level. The Cenozoic sequence is composed of the Lower Freshwater Molasse 
(LFM), mostly composed of alternating fine-grained sandstone, marls, clays, and subordinately lacustrine carbonates. Borehole records reveal that the LFM reaches a thickness of $1300 \mathrm{~m}$ in the southern part of the Geneva region, where the Thônex-01 well is located. This unit is mostly impermeable and therefore considered to form the cover of the geothermal system. However, utilization for heat storage installation in the sand-rich intervals of the LFM unit of the areas of sandstone levels is under investigation (Guglielmetti et al., 2020). The top of the sequence is mostly composed of heterogeneous, up to $120 \mathrm{~m}$ thick glacial, fluvio-glacial, and glacio-lacustrine sequences of Quaternary age (Moscariello, 1996; Fiore, 2007). These Quaternary units host the main freshwater resources of the Canton of Geneva and are of great interest for shallow, low-enthalpy geothermal installations.

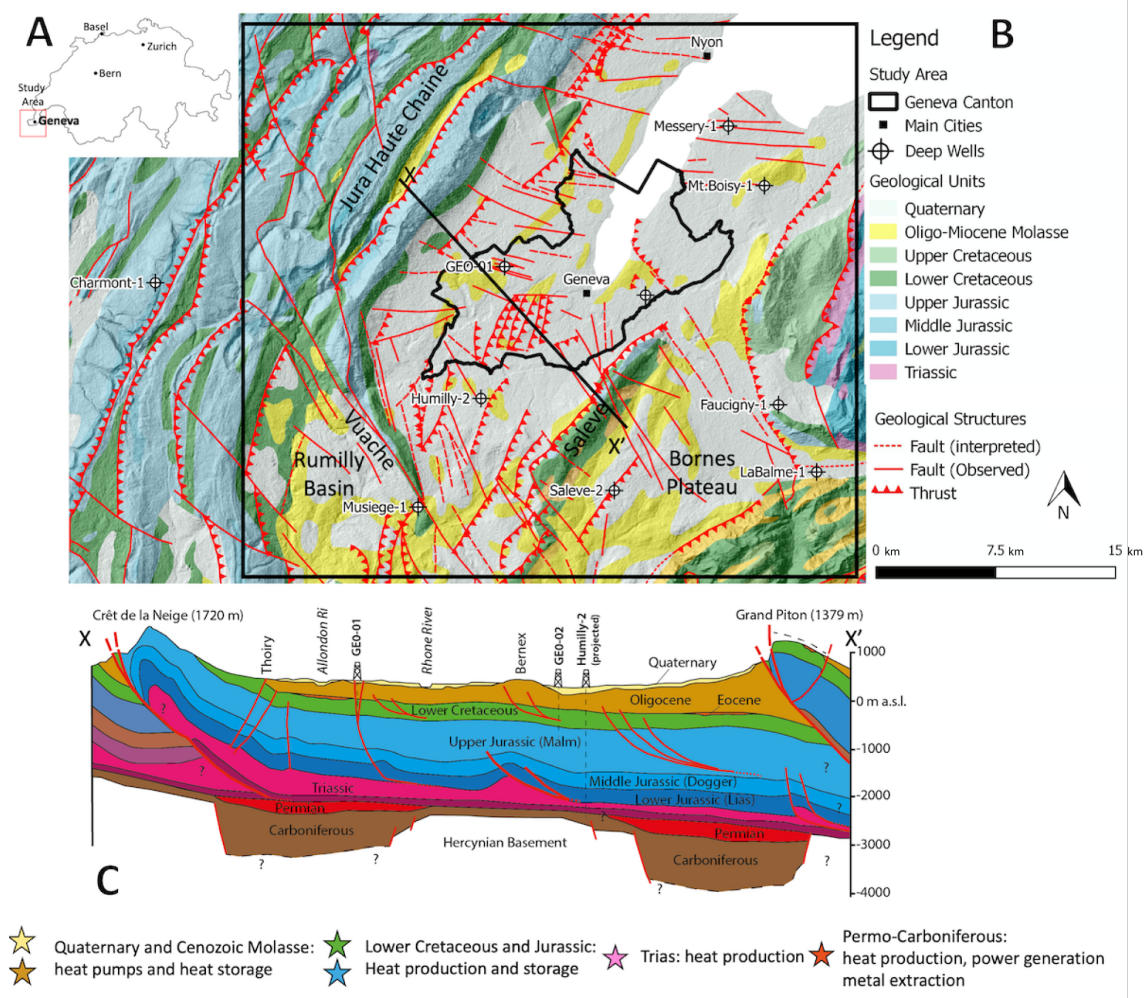

Figure 1: a) Map of Switzerland with the location of the study area; b) Geological map over the Geneva Basin with an indication of the main fault structures and deep wells (modified from Clerc and Moscariello (2020); c) Cross-section cutting through the GB (modified from Moscariello (2019)) indicating the main geothermal targets.

\subsection{Gravity dataset of the study area}

The Swiss Molasse Plateau is part of a large negative anomaly that characterizes the entire northern sector of the Alpine orogen and is associated with the flexural response to Alpine loading (Pfiffner et al., 2002). In the Western Alps, the gravity disturbance is characterized by a positive-negative trend like many other mountain ranges (Karner and Watts, 1983). The trend is NW-SE trend, decreasing gently from the Bresse Graben towards the Pennidic Nappes and then increases abruptly to form the Ivrea-body (IB) anomaly (Fig. 2). Over the Swiss Molasse Plateau and the SwissFrench border, land and airborne gravity data have been collected in the past Verdun et al. (2003); Massona et al. (1999) and the gravity disturbance shows a NW-SE regional trend, controlled by crustal thickening (Klingelé, 2006). Several gravity studies have been conducted over the Swiss Plateau in conjunction with geothermal exploration. Particularly in Eastern and Central Switzerland gravity studies have been used to delineate geologic structures in the top $4 \mathrm{~km}$ to $5 \mathrm{~km}$ as geothermal targets. Integration of gravity data and 3D geologic modeling based on reflection seismic data have been proposed to identify deep PC structures in the St. Gallen area and Neuchâtel area (Altwegg, 2015). Furthermore, pseudo-tomography using sequential Butterworth filtering was applied in Northern Switzerland in a very similar geologic context as in Geneva to match the wavelength content of the gravity signal with geologic features located 
at different depths (Abdelfettah et al., 2014). Integration of 2D seismic wells data has been proposed to calibrate the inversion of gravity data in the GB (Carrier et al., 2020). Gravity data were collected in the Geneva area and surrounding regions for hydrocarbon-resource exploration and research studies. Gravity surveys carried out across the whole Geneva canton reveal the potential of gravity methods in delineating shallow Quaternary features as well as deeper structures such as the transgressive contact of the Cenozoic Molasse on the Mesozoic units (Guglielmetti and Moscariello, in press). For this study, a total of 3558 public gravity data from the gravimetric Atlas of Switzerland (Olivier et al., 2002) and from the International Gravimetric Bureau (Wilmes et al., 2009) have been used (Fig 2). The minimum distance between stations is $100 \mathrm{~m}$.

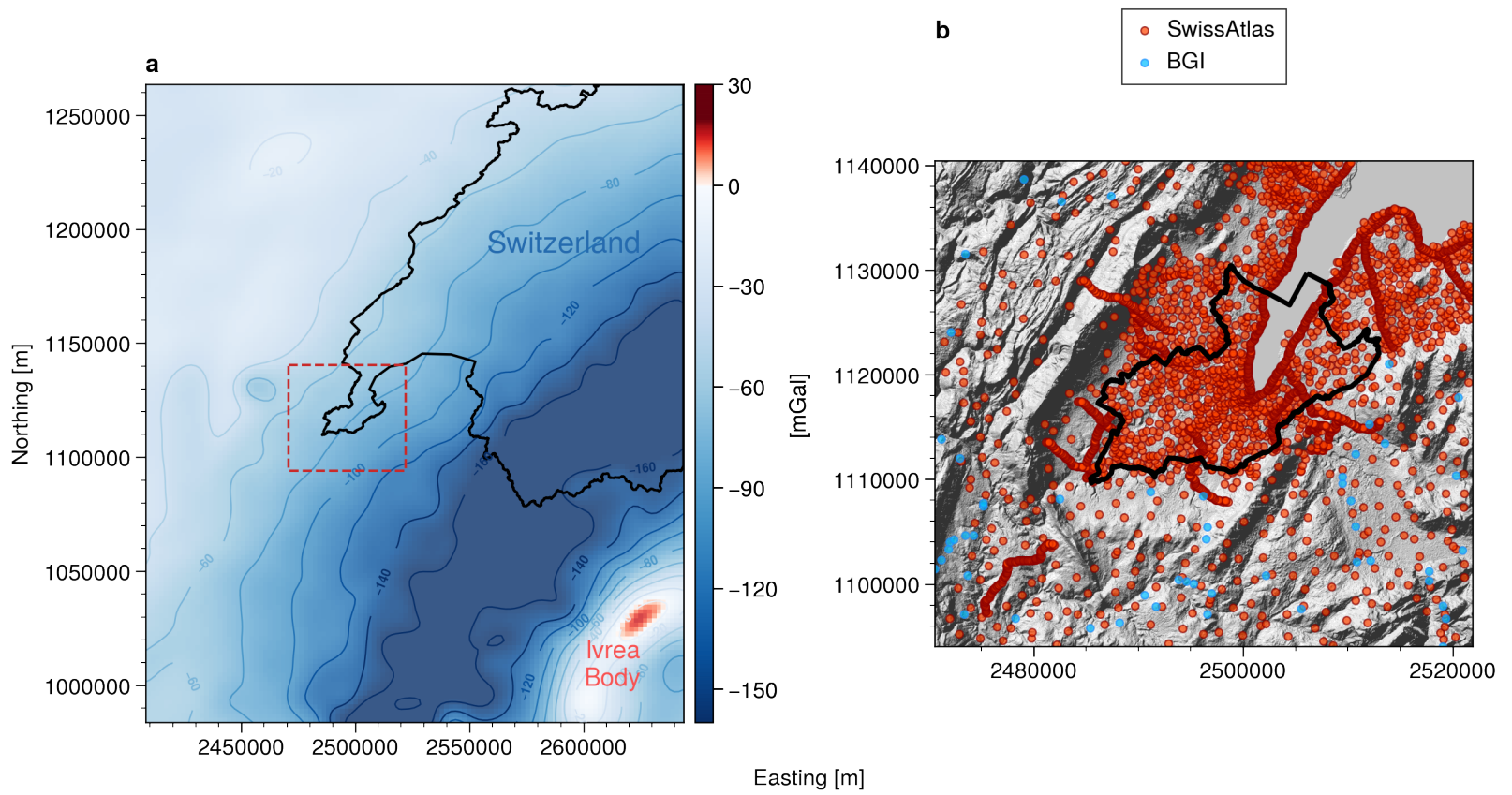

Figure 2: a) Gravity disturbance over the west Alps; b) Gravimetric dataset used in the study area.

\subsection{Gravity disturbance vs. gravity anomaly}

In geophysics, gravity measurements are used to learn about the density variations of the Earth's interior ( $\mathrm{Li}$ and Götze, 2001). Since the gravity vector is the sum of the gravitational and centrifugal accelerations felt by a body, geophysicists are usually only interested in the gravitational component of the observed gravity because that is what reflects the Earth's internal density distribution. The first step toward isolating the gravitational component is to apply gravity reduction to the the gravity measurements. If these effects are properly removed, the resulting observations are considered to be solely the sum of the centrifugal acceleration due to the Earth's rotation and the gravitational acceleration produced by the internal density distribution of the whole Earth. The isolation of this particular gravitational component, and its subsequent use for estimating density distributions related to geological structures in the subsurface, are the main goals of the application of the gravity method (Blakely, 1995). The gravity anomaly, which is defined as the difference between the Earth's gravity on the geoid and the normal gravity on the reference ellipsoid, depends only on longitude and latitude and is not a function of the height. Moreover, since it is not defined at the same point, gravity anomaly contains centrifugal accelerations and cannot be considered a harmonic function (Barthelmes, 2009). Contrary to the gravity anomaly, the gravity disturbance is defined as the difference between the Earth's gravity and the normal gravity at the same point. As a result, the centrifugal accelerations is removed from the observed gravity and the disturbance can be considered as a harmonic function (Li and Götze, 2001). For these reasons, the gravity disturbance is the logical choice for representing the gravitational effects produced by the heterogeneous density distribution of the Earth. 


\section{Methodology}

\subsection{Gravity processing \\ 3.1.1. Normal gravity}

The first step of our approach is to compute the ellipsoidal-produced normal gravity. Nowadays, it is possible to calculate the exact theoretical gravity analytically at any latitude and height. Li and Götze (2001) (Appendix A, equation A-2) provide an efficient formulation for the closed formula which can calculate normal gravity at any latitude and height. Further discussion on how to compute normal gravity can be found in Pasteka et al. (2017). The closed formula has been coded in Boule (Uieda and Soler, 2020) a Python library developed for calculating gravity fields for the reference WGS84 ellipsoid as defined by the values given in Hofmann-Wellenhof and Moritz (2006).

By subtracting normal gravity from observed gravity, we obtain the gravity disturbance at each point station. This approach has been recently applied with success by Uieda and Barbosa (2017); Pastorutti and Braitenberg (2019); Motta et al. (2019).

\subsubsection{Topographic correction}

Before a gravimetric survey can be interpreted for anomalous signals, the effect of the topographic masses on the gravity measurements must be calculated and reduced (Hirt et al., 2019). This correction is denoted as a topographic mass reduction (Jacoby and Smilde, 2009) or gravimetric terrain correction (Li and Sideris, 1994). Instead of using the traditional approaches such as planarization that neglect the effect of topographic masses beyond some fixed integration radius (Pasteka et al., 2017), we propose an approach that directly models Earth's topographic masses and their gravity effects using a high-resolution digital elevation model. The gravitational field generated by a layer of prisms in Cartesian coordinates, representing the Earth topography in the study area, has been computed through the analytical solutions given by Nagy et al. (2000) and Nagy et al. (2002). In particular, we used Harmonica (Uieda et al., 2020), a Python library for processing and modeling gravity and magnetic data, which makes use of the modified arctangent function proposed by Fukushima (2020) which could be used to apply the topographic correction for small regions where the curvature of the Earth could be neglected. The spatial resolution of terrain correction computations is important to better resolve and detect small-scale or near-surface mass-density anomalies, e.g., in the context of geophysical exploration (Hirt et al., 2019). The elevation data used in this work comes from the Shuttle Radar Topography Mission (SRTM) Version 3.0 for which the voids are filled with non-commercial Advanced Spaceborne Thermal Emission and Reflection Radiometer (ASTER) Global Digital Elevation Model Version 2 (GDEM 002). This elevation data set has a vertical absolute height error of less than $16 \mathrm{~m}$ and a circular absolute geolocation error of less than $20 \mathrm{~m}$. For computational reasons, the SRTM elevation model has been down-sampled to a cell size of 100 $\mathrm{m} \times 100 \mathrm{~m}$. By subtracting the topographic effect from the gravity disturbance, we obtain the topography-free gravity disturbance.

\subsubsection{Harmonic residuals}

In the previous section, we describe the approach to remove the normal gravity and the effect of topography from the measured gravity. The final result is a value of topography-free gravity disturbance (GDTOPOFREE) at each point station. Generally, the next step consists of removing the regional trend from the GDTOPOFREE and interpolate the residuals to produce a grid that can be imaged or contoured. Removal of a trend is an important step when dealing with geophysical data since most interpolation method can struggle with long-wavelength trends in the data (Uieda, 2018). For this work, in order to keep the harmonic nature of the data, the residuals are obtained by removing the effect of a deep equivalent layer (at $50 \mathrm{~km}$ depth beneath data elevation points) that allow to reproduce only the longwavelength component of the GDTOPOFREE.

\subsection{Residuals interpolation}

In the literature, we can find several gridding techniques applied to gravity data, such as the minimum curvature method (Briggs, 1974), kriging (Marcotte and Chouteau, 1993; Shamsipour et al., 2017), or even better the equivalent source technique (Dampney, 1969; Cooper, 2000) that has the advantage to take into account the 3D nature of the observations, not just their horizontal positions and the fact that potential fields are harmonic functions (Soler and Uieda, 2021). However, a major limitation of these approaches is that they tend to oversample the mean value observed in the data while undersample the extreme low and high that are the most important in resource characterizations. To overcome this limitation we propose to apply geostatistical methods that have the advantage of preserving the variance observed in the data, instead of just the mean value as in deterministic interpolation. Geostatistical simulation, in 
particular, allows for the calculation of many equally probable realizations, which can be post-processed to quantify and assess uncertainty. For this work, we propose to use the sequential Gaussian simulation (Journel and Journel, 1989; Deutsch et al., 1992) technique to generate residuals field realizations and compare the results with the equivalent source technique approach, obtained through the python's Harmonica package (Uieda et al., 2020). In the next sections we briefly describe these two techniques.

\subsubsection{Sequential Gaussian Simulation}

Sequential Gaussian Simulation (SGS) is a commonly used geostatistical technique to stochastically populate a grid with a Gaussian random field (Journel and Journel, 1989; Deutsch et al., 1992). It has been applied in a wide range of disciplines, such as reservoir characterization (Verly, 1993), mining (Dimitrakopoulos et al., 2002), geophysics (Hansen et al., 2006) and environmental sciences (Juang et al., 2004). Stochastic simulations are commonly used to invert gravity data (Shamsipour et al., 2010; Tirdad et al., 2019), however, these methods are rarely used to generate multiple realizations of the gravity field.

An essential aspect of geostatistical modeling is to establish quantitative measures of spatial correlation in the data to be used for subsequent kriging and simulation (Pyrcz and Deutsch, 2014). This correlation is often achieved through variography analysis and in particular by calculation of the experimental variogram on the data. Experimentally, the variogram for lag distance $h$ is defined as the average squared difference of values separated by $h$ :

$$
\hat{\gamma}(h)=\frac{1}{2 N(h)} \sum_{N(h)}[z(u)-z(u+h)]^{2}
$$

where $N(h)$ is the number of pairs for lag $h$. Variogram calculation is preceded by selection of the $z$ variable to use. Although the choice of the variable to use is evident, data transformation is required in geostatistics. In fact, Gaussian techniques need the data to be normal distributed. At the end of the simulation, the transformed data will be back transformed to the original distribution. It is important to note that during the data transformation, so-called normal score transform, the order of the data is preserved, that is, high values before transformation remain high after transformation.

The experimental variogram is not directly usable since noisy results should be discounted, geological interpretation should be used in the construction of the final variogram model, and we need a licit variogram measure for all distances (Pyrcz and Deutsch, 2014). This is achieved by fitting a parametric variogram model to the experimental points by defining the nugget effect (the geological variability at scales smaller than the smallest lag (h) separation in equation 1), the sill (the equal-weighted variance of the data entering variogram calculation, that is equal to 1 if the data are normal scores), and the range of correlation (the distance after which no spatial correlation exists between data). Another important parameter to consider is the geometric anisotropy of the data. In fact, due to depositional processes, variograms are rarely isotropic, and the range of correlation between the pair of data depends on azimuth. Major and minor directions of continuity are generally known from geological interpretation or preliminary contouring of the data; sometimes variogram needs to be calculated in a number of directions to observe directions of greater or lesser continuity (Pyrcz and Deutsch, 2014).

The theoretical foundation of SGS implies that all previously simulated nodes, referred to as neighbours, should be included in the kriging system of each newly simulated node (Nussbaumer et al., 2018). In contrast to standard interpolation techniques such as minimum curvature or equivalent source technique, geostatistical simulation guarantees that realizations reproduce the histogram and spatial continuity model of the residuals. The general sequential Gaussian simulation process could be resumed in the following step:

1. Transform the original data (residuals in our case) to a standard normal distribution. This step is necessary to guarantee that the simulation is done in a "normal" space;

2. Randomly select the next node to simulate in the grid and search for all neighbours data and previously simulated nodes;

3. Perform a simple kriging with these data and previously simulated nodes to obtain kriged mean and the corresponding kriged variance;

4. Drawn the simulated value from a normal distribution with kriged mean and kriged variance, and assign it to the selected node;

5. Repeat steps 1 to 5 until all the grid nodes are simulated, taking into account, for every new cell node, the values previously simulated to ensure that the covariance with this value and all future predictions is correct. By changing the seed at each loop, we obtain a new realization. 
6. Back transform all data and simulated values to the original distribution when the grid is fully populated.

Sequential Gaussian simulation technique has been extensively explained in the literature, therefore, the authors refers to Chiles and Delfiner (2009); Pyrcz and Deutsch (2014); Nussbaumer et al. (2018) for a more detailed description.

\subsubsection{Equivalent layer technique}

A widely used method for interpolating potential fields such as gravity data is the equivalent source technique (also known as equivalent layer (EQL), radial basis functions, or Green's functions interpolation), introduced by Dampney (1969). For this work, we used an equivalent layer technique in which the point sources are located beneath the observed potential-field measurement points by default (Cooper, 2000). Coefficients associated with each point source are estimated through linear least-squares with damping (Tikhonov $0^{\text {th }}$ order) regularization, which defines how much smoothness is imposed on the estimated coefficients. The Green's function for point mass effects used is the inverse Cartesian distance between the grid coordinates and the point source is defined as:

$$
\phi\left(\tilde{x}, \tilde{x}^{\prime}\right)=\frac{1}{\left\|\tilde{x}-\tilde{x}^{\prime}\right\|}
$$

where $\tilde{x}$ and $\tilde{x}^{\prime}$, are the coordinate vectors of the observation point and the source, respectively. For a more detailed description of the equivalent layer technique, the authors refers to the original papers of Dampney (1969) and to the work of Soler and Uieda (2021).

\subsection{Uncertainty quantification}

Gravity field interpolation allow to image anomalies in the subsurface. Generally, the next step require to invert these data in order to obtain reliable information on subsurface density anomalies. Stochastic approaches such as the SGS have the advantage to generate multiple, equally probable, interpolation of the gravity field that matches the available gravity stations and that can be independently inverted to account for spatial data uncertainty. On the other hand, deterministic interpolation techniques such as the equivalent layer, produce a unique smoothed and continuous interpolation of the data, that suit well for derivative-based inversion commonly used in potential field, but which is not adequate to quantify spatial uncertainty. Moreover, the SGS realizations guarantees the reproduction of high values, that is impossible to reproduce with deterministic approaches that by definition reproduce only the mean value of the data.

\section{Results}

\subsection{Gravity processing}

Figure 3 compares the results of a traditional gravity processing approach (Fig. $3 \mathrm{~b}$ to $3 \mathrm{e}$ ) that use approximation formulas for computing the gravity corrections, with the proposed approach (Fig. 3f to 3i) that allow computing the normal gravity analytically and that use a forward approach for modeling the effect of topographic masses over the survey area. The far-right column of Figure 3 shows the difference between the two approaches, for each processing step.

\subsubsection{Gravity disturbance}

The normal gravity, computed using the Somigliana's formula and the free-air correction (Fig. 3b) slightly underestimates the normal gravity computed using the analytical form (Fig. 3f), by almost $1 \mathrm{mGal}$ in regions where the topography is more pronounced, as shown in (Fig. 3j). The minimum, maximum, mean, and standard deviation values for the normal gravity using both approaches are resumed in Table 1.

By subtracting the normal gravity from the observed gravity, we obtain the so-called free-air anomaly for the traditional approach (Fig. 3c) and the gravity disturbance for the proposed approach (Fig. 3g). Both approaches show similar results; the gravity disturbance is positive where the topography is greater and negative where the topography is lower than the WGS84 ellipsoid as defined by the values given in Hofmann-Wellenhof and Moritz (2006). As for the normal gravity, the higher the topography, the greater the difference reaching almost $1 \mathrm{mGal}$ over the Jura mountains. 

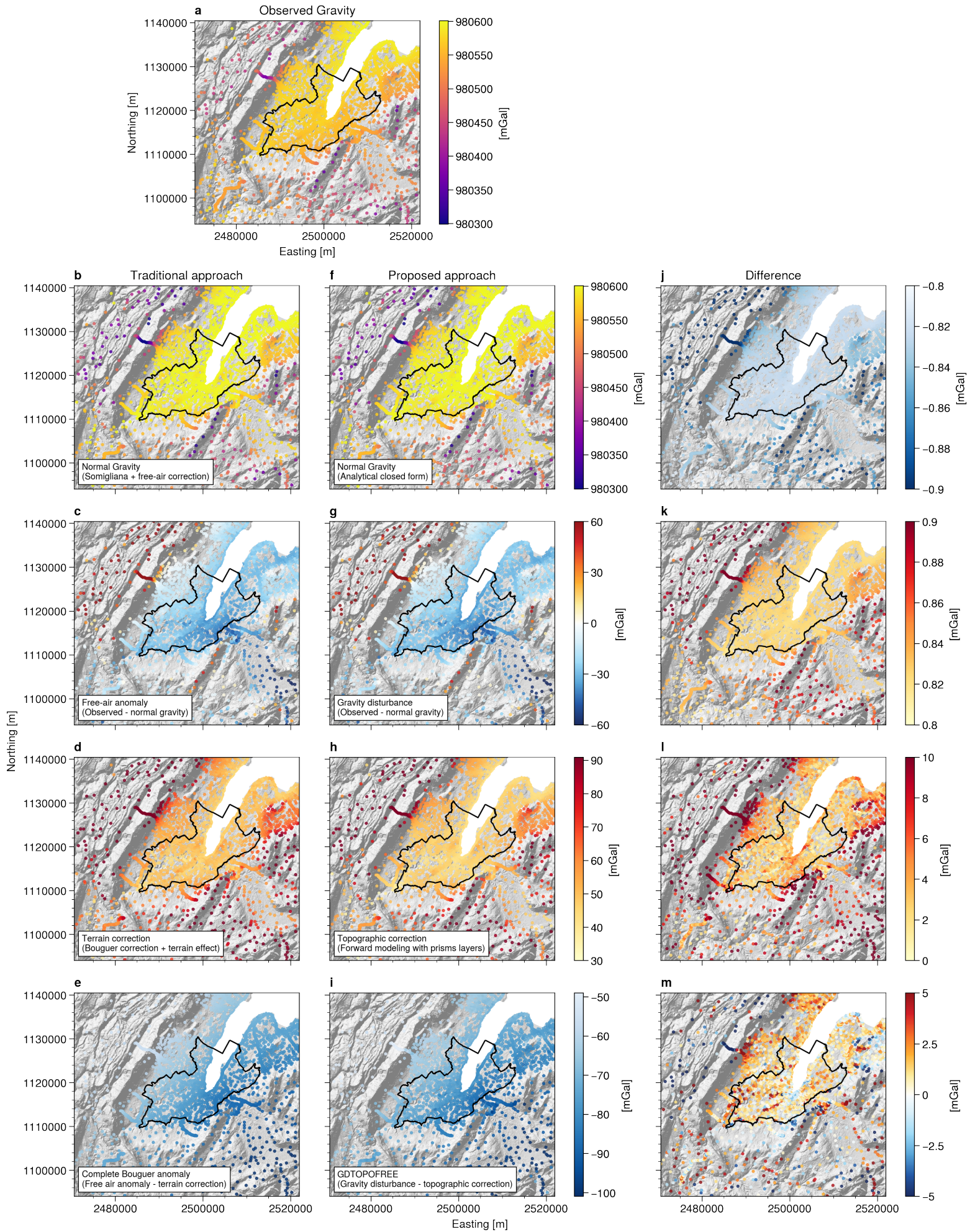

Figure 3: Processing workflow: a) Observed gravity; b) to e) Traditional processing workflow; f) to i) Proposed approach; j) to $m$ ) Difference between the two approaches. See the text for detailed description of each step. 
Table 1

Difference in correction between the traditional and proposed approach.

\begin{tabular}{lcccccccc}
\hline & \multicolumn{3}{c}{ Normal Gravity [mGal] } & \multicolumn{4}{c}{ Topographic (terrain) correction [mGal] } \\
\cline { 2 - 9 } Method & $\min$ & $\max$ & mean & std & min & max & mean & std \\
\hline Traditional approach & 980255.7 & 980630.4 & 980581.6 & 47.65 & 32.67 & 202.34 & 56.97 & 19.05 \\
Proposed approach & 980256.8 & 980631.3 & 980582.4 & 47.62 & 27.07 & 156.15 & 51.80 & 14.81 \\
\hline
\end{tabular}

\subsubsection{Topographic correction}

The results for the gravitational effect of topographic masses using the prisms layer forward modeling are presented in Figure 3h. Figure 3d shows the results obtained with a planar approximation. The minimum, maximum, mean, and standard deviation values for the topographic correction for both approaches are resumed in Table 1. It is interesting to note that the mean value of the two methods differs by about $5 \mathrm{mGal}$ with a maximum value of more than 200 $\mathrm{mGal}$ when the terrain corrections rely on planar approaches versus a maximum value of about $156 \mathrm{mGal}$ when the effect of topographic masses is generated by a layer of prisms with higher resolution. The greater differences are generally located where the topography is more pronounced, which is normal since the elevation models used for the two approaches are of different resolutions and by using a coarser grid (as in the planar approximation approach), the higher values tend to be smoothed.

Finally, by subtracting the topographic (terrain) correction from the gravity disturbance (free-air anomaly) we obtain the topography-free gravity disturbance (GDTOPOFREE) and the complete Bouguer anomaly (CBA), as shown in figure $3 \mathrm{i}$ and $3 \mathrm{e}$ respectively. Figure $3 \mathrm{~m}$ shows the differences between CBA and GDTOPOFREE, which can reach values of $+/-5 \mathrm{mGal}$.

\subsubsection{Harmonic residuals}

The last step of the processing workflow consists to remove the long-wavelength component from the GDTOPOFREE to obtain residuals. To reproduce the effect of the long-wavelength components and preserve the harmonicity in the data, we predict the effect of an equivalent layer with sources placed at a depth of $50 \mathrm{~km}$. This is shown by Figures $4 \mathrm{a}$ and $4 \mathrm{~b}$, which illustrate the long wavelength of the GDTOPOFREE signal and the resulting harmonic residuals respectively. Figure $4 \mathrm{c}$ shows the distribution and the statistics of the residuals.

\subsection{Imaging the residuals}

To image the residuals over the study area, we need to interpolate them over a regular grid. As described above, we propose to compare a the results obtained using an equivalent layer technique Dampney (1969); Cooper (2000) with a geostatistical approach that gives a better representation of the spatial variability of the gravity field and provides a means for quantifying uncertainty.

\section{Sequential Gaussian simulation}

The geostatistical approach relies on the quantification of the spatial continuity of the variables to estimate or simulate. The first step for computing Sequential Gaussian simulation is to compute the experimental variogram for a variety of directions (Pyrcz and Deutsch, 2014) to identify the direction of the spatial continuity. Figure 5 shows the experimental and modeled variogram, for an azimuth of $30^{\circ}$ corresponding to the "major" direction of continuity and for an azimuth of $120^{\circ}$ corresponding to the "minor" direction of continuity. By fitting a variogram model we obtain the kriging parameters (nugget effect, variogram structure, and the range) that are needed to compute the sequential Gaussian simulation. The data show an important nugget effect of 0.25 indicating a small-scale variability that reflects an error in measurement values or location assigned to the data. Considering that the dataset is a mix of vintage and more recently measurement campaign, a high nugget effect is very likely. The experimental variogram also denotes that the range in the major direction reach $15 \mathrm{~km}$ indicating that behind this distance no spatial correlation exists. Then, 100 SGS realizations have been performed, two of which are presented in Figures 6a and 6b. Pointwise summary statistics may be easily calculated at each location of the simulation grid. Figure $6 \mathrm{c}$ show the expected value (e-type) of each local distribution of uncertainty for the residuals gravity field. This corresponds to the average of all realizations at each location of the simulation grid. The e-type reproduce the residuals at measured station and the global mean away from the data, providing the best local estimate of the residuals field. Figure $6 \mathrm{~d}$ shows the conditional variance, which 

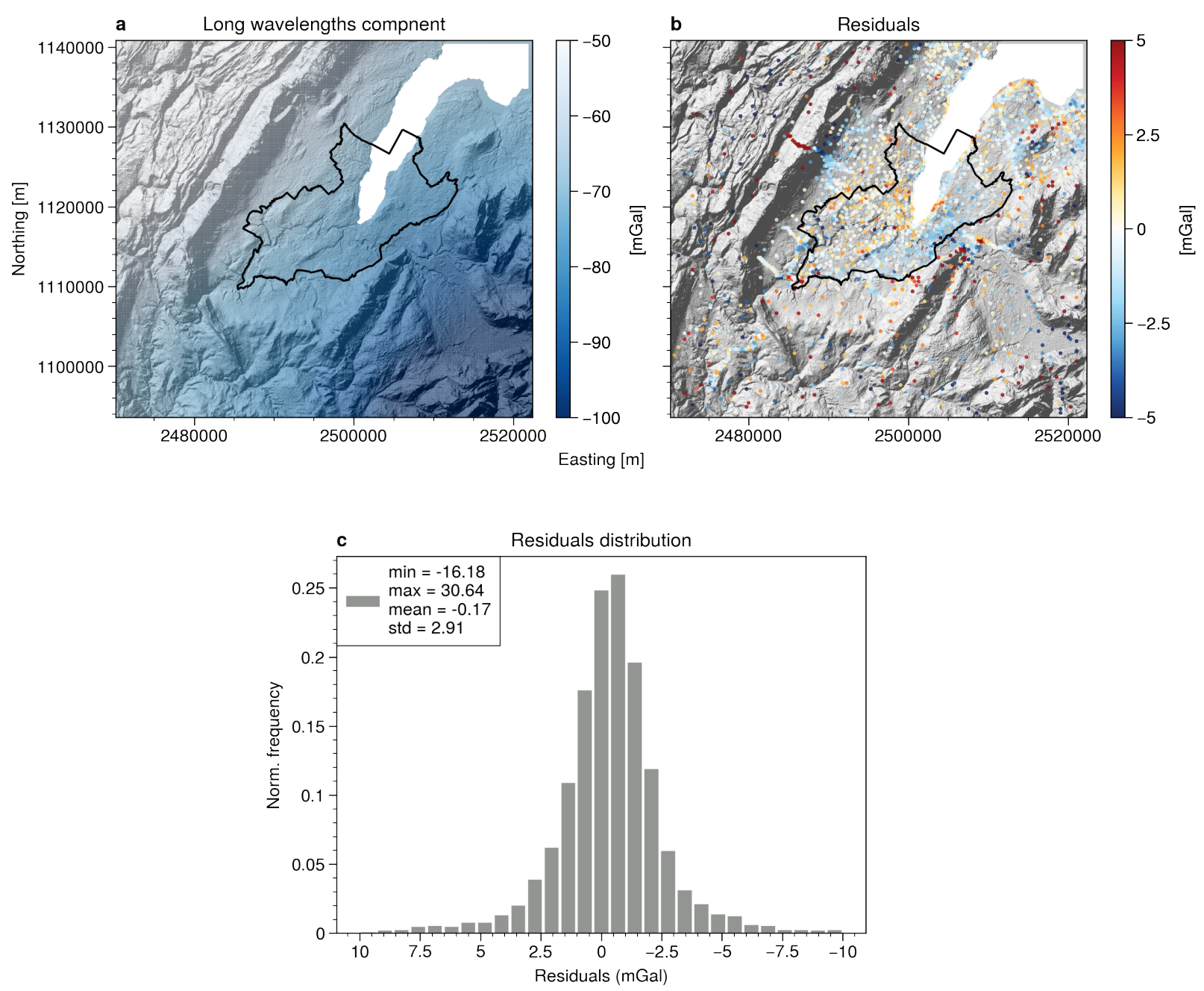

Figure 4: a) Long-wavelength component of the GDTOPOFREE predicted at $50 \mathrm{~km}$ beneath gravity station; b) Residuals for each station; c) Residuals distribution.

corresponds to the variance of the local realizations, at each location of the grid. This map can be used to visualize local uncertainty, reflecting data gaps in the NE and SW as well as along the Jura mountains.

\section{Equivalent layer technique}

Figure 7 shows the interpolation result using the equivalent layer technique obtained by upward continuation at three different heights: 1) height equal to the topography (Fig. 7a); 2) constant height equal to $500 \mathrm{~m}$, corresponding to the mean observations height (Fig. 7b) and 3) constant height equal to $1556 \mathrm{~m}$, corresponding to the largest observations height (Fig. 7c). The equivalent source interpolator is obtained after cross-validating different set of relative depth and damping factor parameters, ranging from $500 \mathrm{~m}$ to $5000 \mathrm{~m}$ and 0.1 to 5.0 respectively. The best result is obtained using a relative depth of $3000 \mathrm{~m}$ and a damping regularization factor of 2.0. Figure $7 \mathrm{a}$ and $\mathrm{b}$ show similar results. However, by performing an upward continuation at a constant height of $1556 \mathrm{~m}$, we obtain a much smoother residuals interpolation.

\section{Comparing SGS and EQL}

In order to compare the results of the equivalent layer technique and the sequential Gaussian simulation, we take into account the upward continuation prediction performed at the station's elevation (Fig.7a). The e-type (Fig. 6c) and the upward continuation show an alternation of positive and negative anomalies in the NE - SW direction, that seems 


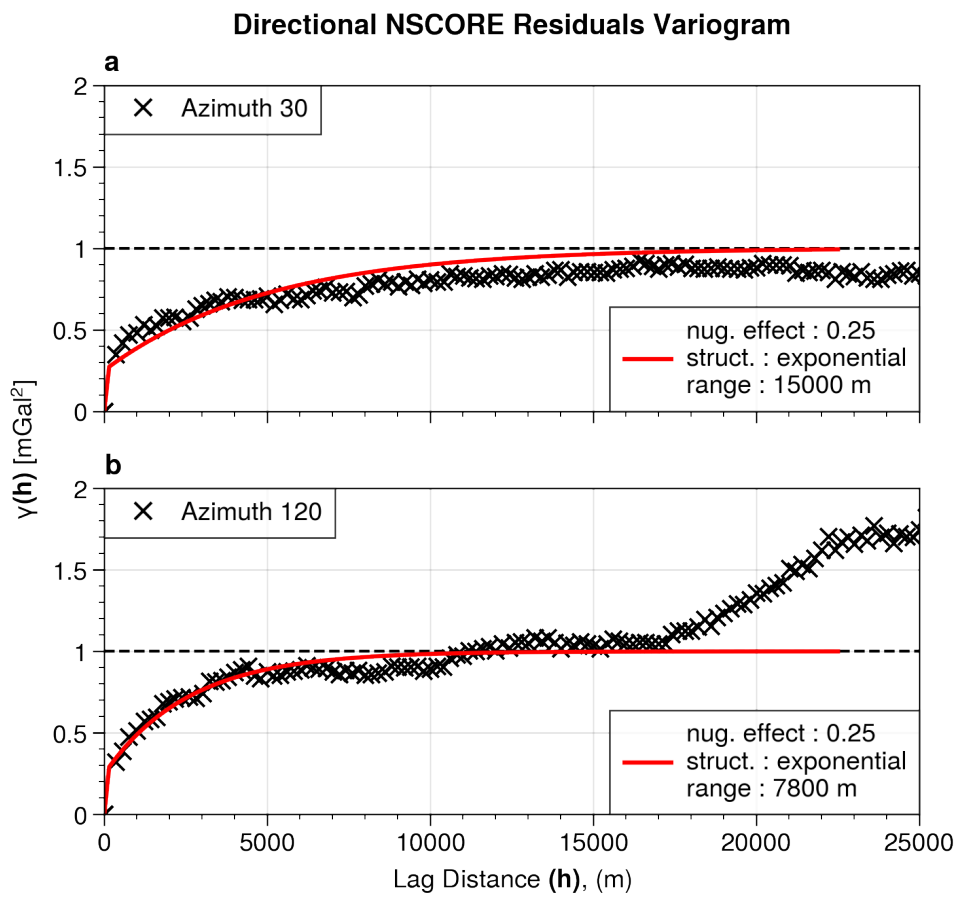

Figure 5: Experimental variogram computed on residuals for the major spatial continuity $30^{\circ}$ and minor $120^{\circ}$ spatial continuity.

to corroborate with the main geological structures of the studied area that have a direction SE-NW as described in Figure 1. The main positive anomalies are associated with the regions where the Mesozoic units are exposed as in the Jura mountains, and Saleve Ridge, and in minor parts the Vuache. Particularly, the Saleve Ridge anomaly shows high values in the SGS results than in the EQL results, higlighting the ability, for SGS realizations, to reproduce the extreme values of the residuals distribution. Three main negative anomalies are observed in the north-west (1), south-west (2), and south-east (3) parts of the study area.

1. The NW anomaly is located in the Jura Mountains, where the Cretaceous and Jurassic limestones are the only exposed lithologies. This anomaly became narrower in the S-SW. The source of this anomaly is unclear. Small outcrops of Triassic limestones and anhydrites are exposed in the surrounding region (Figure 1a), and likely extends at 1-2 $\mathrm{km}$ in depth below the Cretaceous and Jurassic limestones as indicated by seismic data in the area (Gorin et al., 1993). Triassic lithologies can have lower density compared to the surrounding Cretaceous and Jurassic limestones and are often affected by decoupling along with the main detachment, with subsequent repetitions as observed in the Charmont- 1 well, located about $10 \mathrm{~km}$ to the West from Anomaly A (outside of this map). The contribution of P-C sediments, drilled at rather shallow depth (1793m-2291m MD) can also be considered a possible source of this anomaly, at least partially. The EQL results around this anomaly are affected by boundary effect (high positive anomaly in the NW corner of the study area). On the other hands, SGS results show the same negative anomaly without be affected by a boundary numerical effect.

2. This anomaly is located at the Rumilly Basin, where the main formations cropping out are the Quaternary and Tertiary sediments and their total thickness is estimated to be around $500 \mathrm{~m}$. The Musiege- 1 well is located at the south-eastern boundary of this anomaly in the proximity of the Vuache Fault, where the well encountered $150 \mathrm{~m}$ of Molasse sediments above the Lower Cretaceous limestones Moscariello et al. (2014). This values of this anomaly seems to be smoothed in the EQL results compared to the SGS realizations and e-type.

3. The third negative anomaly can be associated with the thick sequence of Molasse sediments filling the Bornes Plateau where the Saleve-2 well reached the base of the Cenozoic sediments at $1750 \mathrm{~m}$ and the Faucigny-1 well at $2915 \mathrm{~m}$. 


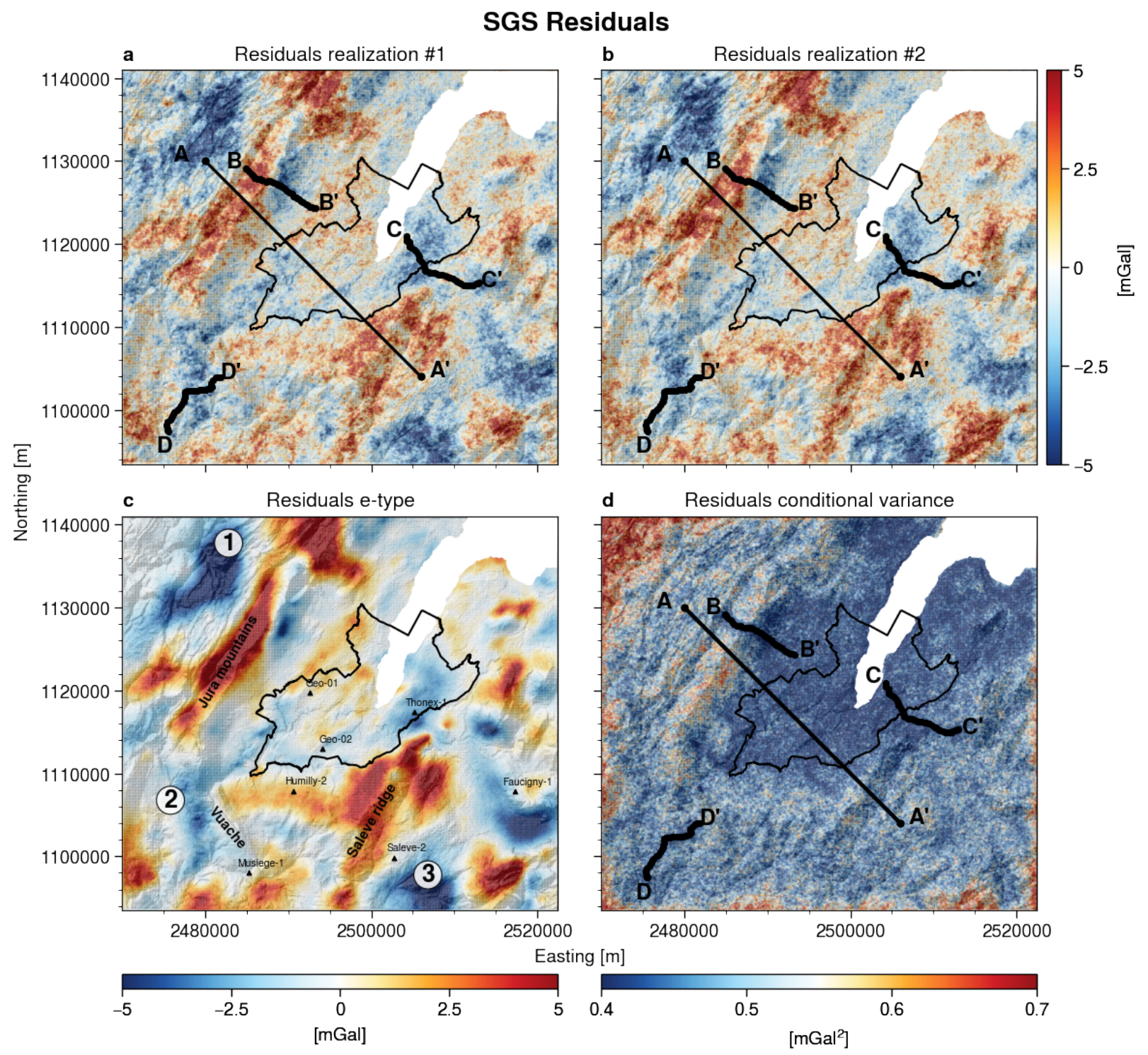

Figure 6: Results of the geostatistical simulation: a) and b) two randomly realizations; c) e-type and c) conditional variance map.

It is not surprising that the aforementioned anomalies show high variability, due to the heteroscedastic nature of geological parameters that commonly show a higher variability for high values and a lower variability for low values (Linsel et al., 2020). This is illustrated in single stochastic realizations (Fig. 6a and b) as well as in the residual profiles plot shown in figure 8 . Figure $8 \mathrm{~b}$, shows the equivalent layer interpolation, the e-type and two SGS realizations along the profile A-A'. The general trend of SGS e-type and the EQL interpolation is almost identical except where the conditional variance is higher (around $3 \mathrm{~km}, 8 \mathrm{~km}$ and $33 \mathrm{~km}$ ). It is also important to remark that when the conditional variance is close to 0 the equivalent layer (blue) and the e-type (dark red) profile shows a very similar trend with values close to 0 . In fact, when the residuals are close to 0 , there is not much variability between realizations and the results obtained with the EQL interpolators and the e-type are very similar.

Profiles B-B', C-C', and D-D' (figures 8c,d and e shows the equivalent layer interpolation, the e-type and two SGS along three gravity stations profiles which are compared with the observed residuals (yellow line): 

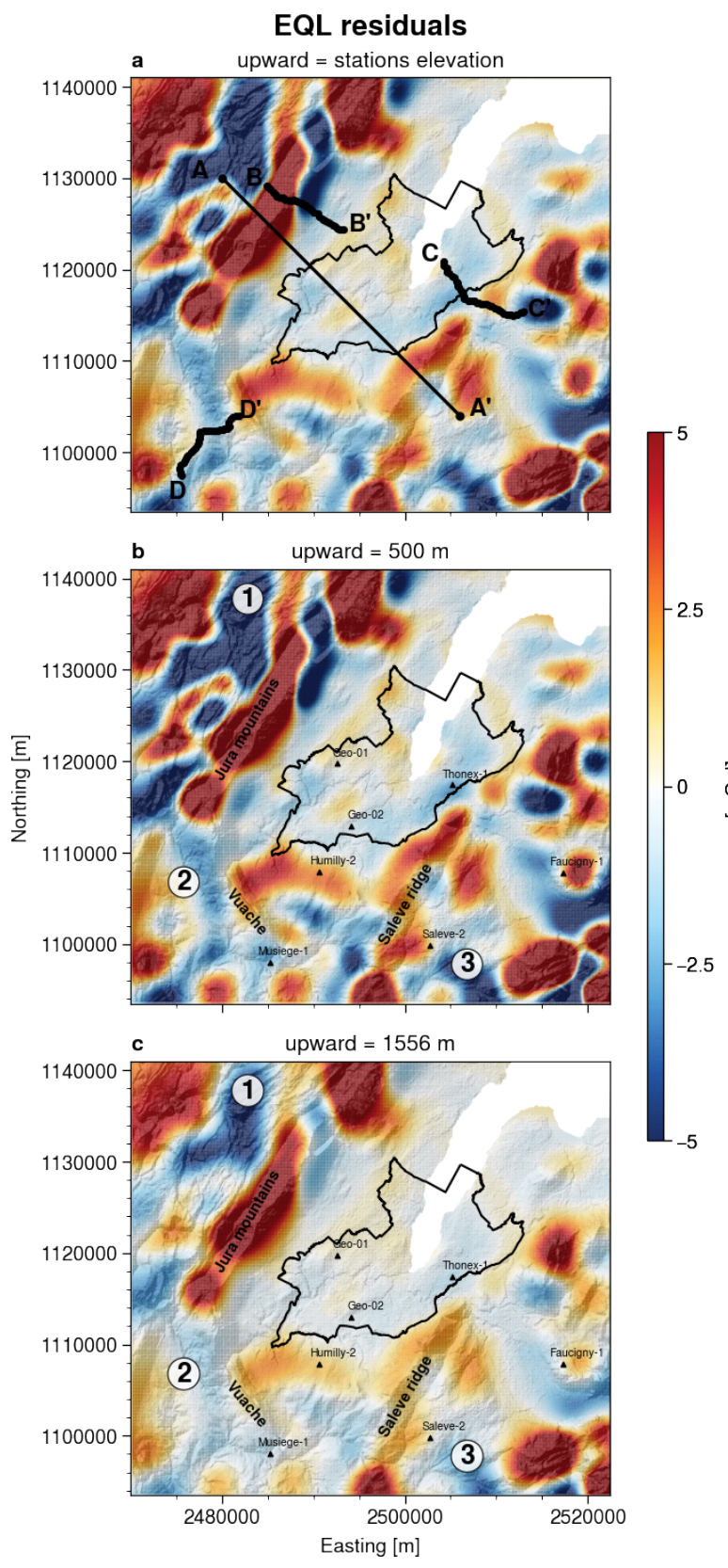

Figure 7: Upward continuation at: a) stations elevation; b) constant height of $500 \mathrm{~m}$ and c) constant height of $1556 \mathrm{~m}$. See the text for a detailed description.

- Profile 1 (8c) shows a good correlation between EQL, e-type and the observed residuals in the SE part of the profile (6 $\mathrm{km}$ to $10 \mathrm{~km}$ along the profile), where the residuals are close to $0 \mathrm{mGal}$. However, for the positive anomaly located in the NE part of the profile ( $0 \mathrm{~km}$ to $3 \mathrm{~km}$ along the profile), the EQL technique seems to over estimate the residuals while the SGS e-type and realizations seem to better represents the observed values.

- Profile 2 (8d) shows a good correlation between EQL, SGS e-type and the observed residuals all along the profile. However, the EQL technique seems to smooth the value in the NW section of the profile ( $0 \mathrm{~km}$ to $5 \mathrm{~km})$. In contrast, the SGS realization better represents the residual values as demonstrated by the SGS real. 2 with the high anomaly at $8.5 \mathrm{~km}$ and the low anomaly at $10 \mathrm{~km}$. 

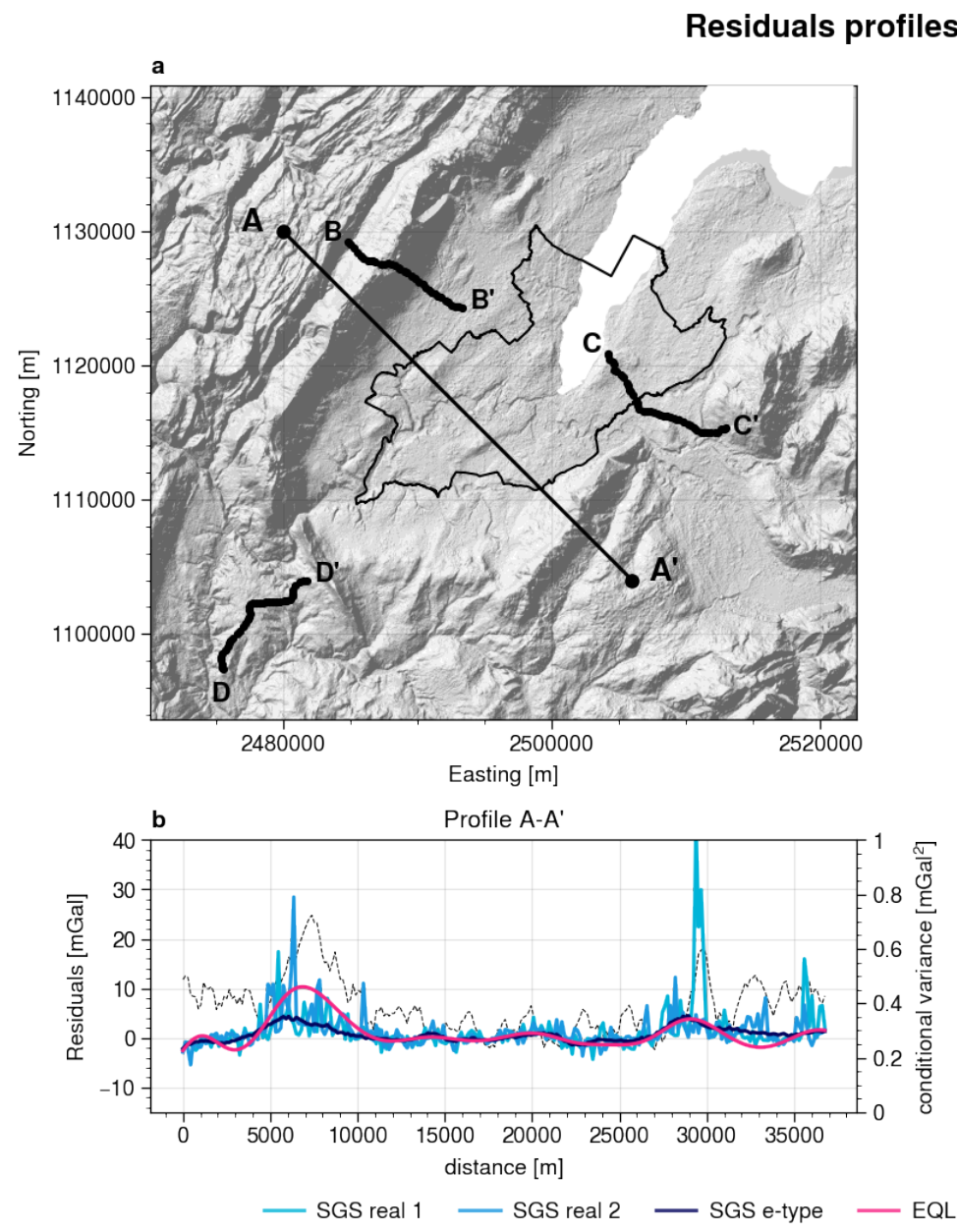
profile.
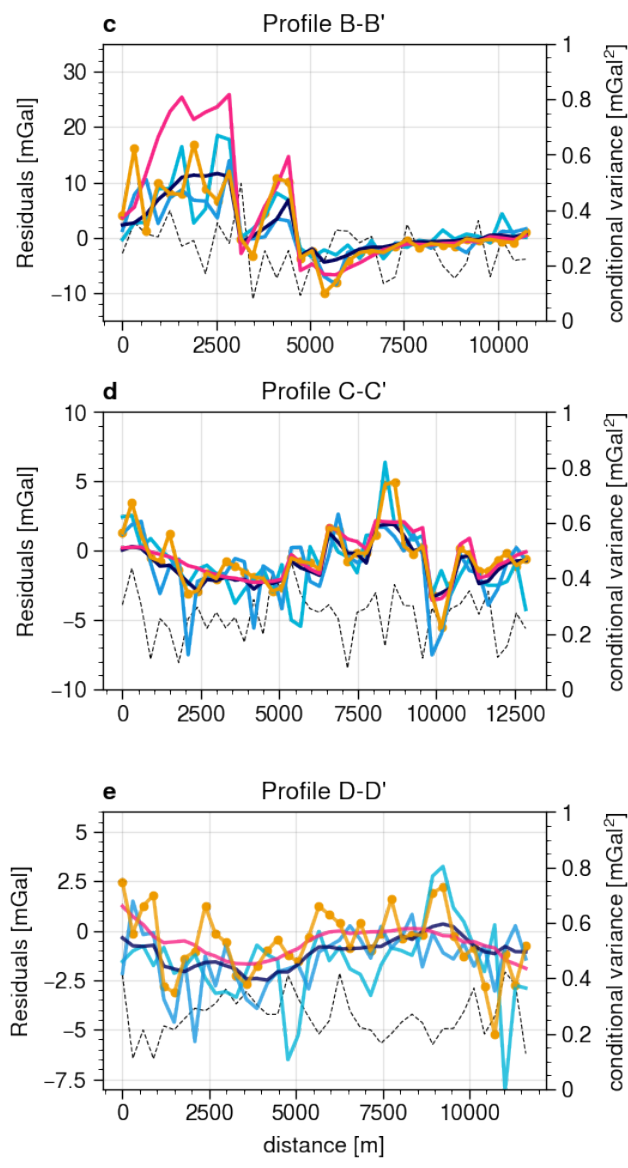

- Profile 3 (8e) shows a profile in the SW part of the study area. The correlation between the interpolated and the observed residuals is poor. Even the correlation between the EQL and SGS e-type poorly match all along the

-.--.- SGS conditional variance

Figure 8: a) Profiles localisation; b) Profile along arbitrary line A-A'; c) to e) profiles along gravity stations.

\section{Discussion}

To properly know about the Earth's interior, we should compare the observed gravity to that of ellipsoidal-produced normal gravity values at each observation station ( $\mathrm{Li}$ and Götze, 2001). In exploration geophysics, the normal gravity is commonly approximated using the Somigliana formula (Somigliana, 1929) and the height correction (also called freeair). The difference between the observed gravity and this approximation is the so-called free-air anomaly. Traditionally, geophysicists use the elevation as the vertical position of the gravity station and the topographic model. The elevation is used in all the corrections including the height correction and the complete Bouguer correction. However, as pointed out by Gumert (1985), the free-air varies significantly with horizontal position and can affect the reduction of observed gravity data. Land gravity measurements made at varying elevations in an area of rugged topography, processed using the standard accepted free-air factor, can produce highly erroneous maps. Our approach for processing gravity data demonstrates that the free-air correction step is outdated. Thanks to the increased computational performance, 
nowadays it is possible to use open source software such as Boule (Uieda and Soler, 2020), which uses a closed-form expression to compute normal gravity anywhere outside of the ellipsoid. This means that free-air approximation is completely unnecessary. The same is valid for the topographic (or terrain) correction. Even if the Bouguer correction is fast and practical, you need a prism model to correct the flaws of the Bouguer correction. Instead, with the proposed approach we are able to directly compute the effect of topography through the prism layer forward modeling approach, and we do not need to do a Bouguer correction at all.

Imaging gravimetric residuals using a stochastic approach instead of a classical interpolation technique has several advantages. Firstly, the spatial uncertainty can be modeled through an anisotropic variogram, allowing taking into account the geological continuity as well as the small-scale variability, indicated by a high nugget effect, that probably reflect an error in measurement values or station location. Secondly, since stochastic simulation preserves both the mean and the variance observed in the data, they can reproduce the extreme value encountered in the distribution. Instead, classical interpolation techniques, preserve only the mean value observed in the data and tends to produce images that are smoothed in which the interpolated value is close to the mean value, and the extreme values are underrepresented. This has been confirmed by comparing the sequential Gaussian simulation and the equivalent layer technique results with the observed residuals along profiles B-B', C-C', and D-D' as shown on figure 8. Finally, since the stochastic realizations represent an equiprobable gravity residual fields that matches the available gravity stations, they can be independently inverted to account for spatial data uncertainty. The capacity, for the sequential Gaussian simulation approach, of generating equiprobable realizations which reproduce the extreme distribution values is critical for georesources exploration. Indeed, the high (or low) anomalies in exploratory geophysical methods are generally associated with favourable economic conditions. This has been proved in water, mining and oil and gas exploration, where geostatistical simulation techniques are employed as a regular approach for imaging and inverting exploratory geophysical data, such as gravity, electromagnetic or seismic as not to miss any economically favourable target.

\section{Conclusions}

An approach allowing the processing of gravimetric data in a two-step workflow using analytical approaches instead of approximations is presented. Firstly, the normal gravity is computed analytically and subtracted to the observed gravity in order to obtain the gravity disturbance. Then, a forward approach is used to compute the gravitational effect of topographic masses that is removed to the gravity disturbance. By using Boule and Harmonica Python packages, we demonstrate that gravity processing could be accurately done using open source tools. Secondly, we present a stochastic approach to image the gravimetric residuals. The main advantage of this approach is not only that each stochastic realization reproduces the distribution of the data, instead of the mean value, but also that each independent realization could be stochastically inverted to account for spatial uncertainty on the data. These are key aspects when uncertainties need to be taken into account in the context of decision-making processes supporting geo-energy exploration activities in sedimentary basins.

\section{Acknowledgments}

We are indebted to the developers and maintainers of the Boule and Harmonica open-source software without which this work would not have been possible. In particular, we would like to thank Santiago R. Soler, Leonardo Uieda for fruitful discussion in the Fatiando Slack community (https://fatiando.slack.com/) as well as Erwan Gloaguen for constructive discussion about geostatistical approaches. This work is part of the GECOS, an INNOSUISSE supported project no. 26728.1 PFIW-IW. 


\section{References}

Abdelfettah, Y., Schill, E., and Kuhn, P. (2014). Characterization of geothermally relevant structures at the top of crystalline basement in Switzerland by filters and gravity forward modelling. Geophysical Journal International, 199(1):226-241.

Altwegg, P. (2015). Gravimetry for geothermal exploration. PhD thesis, Université de Neuchâtel.

Barthelmes, F. (2009). Definition of functionals of the geopotential and their calculation from spherical harmonic models: theory and formulas used by the calculation service of the International Centre for Global Earth Models (ICGEM), http://icgem. gfz-potsdam. de.

Blakely, R. (1995). Potential Theory in Gravity and Magnetic Applications.

Brentini, M. (2018). Impact d'une donnée géologique hétérogène dans la gestion des géo-ressources: analyse intégrée et valorisation de la stratigraphie à travers le bassin genevois (Suisse, France). $\mathrm{PhD}$ thesis, University of Geneva.

Briggs, I. C. (1974). Machine contouring using minimum curvature. Geophysics, 39(1):39-48.

Carrier, A., de Bono, C. N., and Lupi, M. (2020). Affordable gravity prospection calibrated on improved time-to-depth conversion of old seismic profiles for exploration of geothermal resources. Geothermics, 86:101800.

Chelle-Michou, C., Do Couto, D., Moscariello, A., Renard, P., and Rusillon, E. (2017). Geothermal state of the deep western Alpine Molasse basin, France-Switzerland. Geothermics, 67:48-65.

Chiles, J.-P. and Delfiner, P. (2009). Geostatistics: modeling spatial uncertainty, volume 497. John Wiley \& Sons.

Clerc, N. and Moscariello, A. (2020). A revised structural framework for the Geneva Basin and the neighboring France region as revealed from 2D seismic data: implications for geothermal exploration. Swiss Bulletin für angewandte Geologie, 25/1+2:value here109-131.

Clerc, N., Rusillon, E., Moscariello, A., Renard, P., Paolacci, S., and Meyer, M. (2015). Detailed structural and reservoir rock typing characterisation of the Greater Geneva Basin, Switzerland, for geothermal resource assessment. In Proceedings World Geothermal Congres.

Cooper, G. (2000). Gridding gravity data using an equivalent layer. Computers \& Geosciences, 26(2):227-233.

Dampney, C. (1969). The equivalent source technique. Geophysics, 34(1):39-53.

Deutsch, C. V., Journel, A. G., et al. (1992). Geostatistical software library and user's guide. New York, 119(147).

Dimitrakopoulos, R., Farrelly, C., and Godoy, M. (2002). Moving forward from traditional optimization: grade uncertainty and risk effects in open-pit design. Mining Technology, 111(1):82-88.

Fiore, J. T. (2007). Quaternary subglacial processes in Switzerland: Geomorphology of the Plateau and seismic stratigraphy of Western Lake Geneva. PhD thesis, University of Geneva.

Fukushima, T. (2020). Speed and accuracy improvements in standard algorithm for prismatic gravitational field. Geophysical Journal International, 222(3):1898-1908.

GeoMol Team (2015). GeoMol - Assessing subsurface potentials of the Alpine Foreland Basins for sustainable planning and use of natural resources. Technical report, Augsburg, LfU.

Gorin, G., Signer, C., and Amberger, G. (1993). Structural configuration of the western Swiss Molasse Basin as defined by reflection seismic data. Eclogae Geologicae Helvetiae, 86(3):693-716.

Guglielmetti, L., Comina, C., Abdelfettah, Y., Schill, E., and Mandrone, G. (2013). Integration of 3D geological modeling and gravity surveys for geothermal prospection in an Alpine region. Tectonophysics, 608:1025-1036.

Guglielmetti, L., Eichinger, F., and Moscariello, A. (2020). Geochemical Characterization of Geothermal Waters Circulation in Carbonate Geothermal Reservoirs the Greater Geneva Basin (GGB). In Proceedings World Geothermal Congress, page .

Guglielmetti, L. and Moscariello, A. (in press). On the use of gravity data in delineating geologic features of interest for geothermal exploration in the Geneva Basin (Switzerland): prospects and limitations. Swiss Journal of Geosciences, in press.

Gumert, W. (1985). Advantages of continuous profiling airborne gravity surveys. In Proceedings of the International Meeting on Potential Fields in Rugged Topography, pages 16-18.

Hansen, T. M., Journel, A. G., Tarantola, A., and Mosegaard, K. (2006). Linear inverse gaussian theory and geostatistics. Geophysics, 71(6):R101R111.

Heuberger, S., Roth, P., Zingg, O., Naef, H., and Meier, B. P. (2016). The St. Gallen Fault Zone: a long-lived multiphase structure in the North Alpine Foreland Basin revealed by 3D seismic data. Swiss Journal of Geosciences, 109(1):83-102.

Hirt, C., Yang, M., Kuhn, M., Bucha, B., Kurzmann, A., and Pail, R. (2019). SRTM2gravity: an ultrahigh resolution global model of gravimetric terrain corrections. Geophysical Research Letters, 46(9):4618-4627.

Hofmann-Wellenhof, B. and Moritz, H. (2006). Physical geodesy. Springer Science \& Business Media.

Jacoby, W. and Smilde, P. L. (2009). Gravity interpretation: fundamentals and application of gravity inversion and geological interpretation. Springer Science \& Business Media.

Jenny, J., Burri, J.-P., Muralt, R., Pugin, A., Schegg, R., Ungemach, P., Vuataz, F., and Wernli, R. (1995). Le forage géothermique de Thônex (Canton de Genève): Aspects stratigraphiques, tectoniques, diagénétiques, géophysiques et hydrogéologiques. Eclogae Geologicae Helvetiae, 88(2):365-396.

Journel, A. G. and Journel, A. G. (1989). Fundamentals of geostatistics in five lessons, volume 8. Wiley Online Library.

Juang, K.-W., Chen, Y.-S., and Lee, D.-Y. (2004). Using sequential indicator simulation to assess the uncertainty of delineating heavy-metal contaminated soils. Environmental Pollution, 127(2):229-238.

Karner, G. and Watts, A. (1983). Gravity anomalies and flexure of the lithosphere at mountain ranges. Journal of Geophysical Research: Solid Earth, 88(B12):10449-10477.

Kempf, O. and Pfiffner, O. A. (2004). Early Tertiary evolution of the North Alpine Foreland Basin of the Swiss Alps and adjoining areas. Basin Research, 16(4):549-567.

Klingelé, E. (2006). Systematic analysis of the Bouguer anomalies of Switzerland. Rapp. Annu. Comm. Suisse Géophysique CSGP.

Li, X. and Götze, H.-J. (2001). Ellipsoid, geoid, gravity, geodesy, and geophysics. Geophysics, 66(6):1660-1668.

Li, Y. and Sideris, M. (1994). Improved gravimetric terrain corrections. Geophysical Journal International, 119(3):740-752. 
Linsel, A., Wiesler, S., Haas, J., Bär, K., and Hinderer, M. (2020). Accounting for Local Geological Variability in Sequential Simulations-Concept and Application. ISPRS International Journal of Geo-Information, 9(6):409.

Lüschen, E., Wolfgramm, M., Fritzer, T., Dussel, M., Thomas, R., and Schulz, R. (2014). 3D seismic survey explores geothermal targets for reservoir characterization at Unterhaching, Munich, Germany. Geothermics, 50:167-179.

Marcotte, D. and Chouteau, M. (1993). Gravity data transformation by kriging. In Geostatistics Tróia'92, pages 249-260. Springer.

Massona, F., Verdun, J., Bayer, R., and Debeglia, N. (1999). Une nouvelle carte gravimétrique des Alpes occidentales et ses conséquences structurales et tectoniques. Comptes Rendus de l'Académie des Sciences-Series IIA-Earth and Planetary Science, 329(12):865-871.

Mazurek, M., Hurford, A. J., and Leu, W. (2006). Unravelling the multi-stage burial history of the Swiss Molasse Basin: integration of apatite fission track, vitrinite reflectance and biomarker isomerisation analysis. Basin Research, 18(1):27-50.

McCann, T., Pascal, C., Timmerman, M., Krzywiec, P., López-Gómez, J., Wetzel, L., Krawczyk, C., Rieke, H., and Lamarche, J. (2006). PostVariscan (end Carboniferous-Early Permian) basin evolution in western and central Europe. Geological Society, London, Memoirs, 32(1):355388.

Moscariello, A. (1996). Quaternary Geology of the Geneva Bay: sedimentary record, palaeoclimatic and paleoenvironmental reconstruction since the Last Glacial Cycle. Terre et environnement, university of geneva, n. 4, 230 pp., University of Geneva.

Moscariello, A. (2019). Exploring for geo-energy resources in the Geneva Basin (Western Switzerland): opportunities and challenges. Swiss Bulletin für angewandte Geologie, 24(2):105-124.

Moscariello, A., Gorin, G., Charollais, J., and Russillon, E. (2014). Geology of Western Switzerland and nearby France in a Geo-Energy perspective. In Proceedings 19th International Sedimentological Congress.

Moscariello, A., Guglielmetti, L., Omodeo Sale, S., De Haller, A., Eruteya, O., Lo, H. Y., Clerc, N., Makhloufi, Y., Do Couto, D., Ferreira De Oliveira, G., Perozzi, L., De Oliveira Filho, F., Hollmuller, P., Quiquerez, L., Nawratil De Bono, C. F., Martin, F., and Meyer, M. (2020). Heat production and storage in Western Switzerland: advances and challenges of intense multidisciplinary geothermal exploration activities, an 8 years progress report. In Proceedings World Geothermal Congress, page 12.

Motta, J., de Souza Filho, C., Carranza, E., and Braitenberg, C. (2019). Archean crust and metallogenic zones in the amazonian craton sensed by satellite gravity data. Scientific reports, $9(1): 1-10$.

Nagy, D., Papp, G., and Benedek, J. (2000). The gravitational potential and its derivatives for the prism. Journal of Geodesy, 74(7-8):552-560.

Nagy, D., Papp, G., and Benedek, J. (2002). Corrections to The gravitational potential and its derivatives for the prism. Journal of Geodesy, 76(8):475-475.

Nussbaumer, R., Mariethoz, G., Gloaguen, E., and Holliger, K. (2018). Which path to choose in sequential gaussian simulation. Mathematical Geosciences, 50(1):97-120.

Olivier, R., Dumont, B., and Klingelé, E. (2002). ). L’Atlas gravimetrique de la Suissee.

Pasteka, R., Mikuska, J., and Meurers, B. (2017). Understanding the Bouguer Anomaly: A Gravimetry Puzzle. Elsevier.

Pastorutti, A. and Braitenberg, C. (2019). A geothermal application for goce satellite gravity data: modelling the crustal heat production and lithospheric temperature field in central europe. Geophysical Journal International, 219(2):1008-1031.

Pfiffner, O.-A., Schlunegger, F., and Buiter, S. (2002). The Swiss Alps and their peripheral foreland basin: Stratigraphic response to deep crustal processes. Tectonics, 21(2):3-1.

Portier, N., Hinderer, J., Riccardi, U., Ferhat, G., Calvo, M., Abdelfettah, Y., and Bernard, J.-D. (2018). New results on the gravity monitoring (2014-2017) of Soultz-sous-Forêts and Rittershoffen geothermal sites (France). Geothermal Energy, 6(1):1-20.

Pyrcz, M. J. and Deutsch, C. V. (2014). Geostatistical reservoir modeling. Oxford university press.

Reynolds, J. M. (2011). An introduction to applied and environmental geophysics. John Wiley \& Sons.

Rusillon, E. (2018). Characterisation and rock typing of deep geothermal reservoirs in the Greater Geneva Basin (Switzerland \& France). PhD thesis, University of Geneva.

SFOE (2018). Energy Strategy 2050 Once the New Energy Act Is in Force.

Shamsipour, P., Chouteau, M., and Marcotte, D. (2017). Data analysis of potential field methods using geostatistics. Geophysics, 82(2):G35-G44.

Shamsipour, P., Marcotte, D., Chouteau, M., and Keating, P. (2010). 3d stochastic inversion of gravity data using cokriging and cosimulation. Geophysics, 75(1):I1-I10.

Soler, S. R. and Uieda, L. (2021). Gradient-boosted equivalent sources.

Somigliana, C. (1929). Teoria generale del campo gravitazionale dell'ellissoide di rotazione. Memorie della società astronomica italiana, 4:425.

Tirdad, S., Gloaguen, E., Bouchedda, A., and Dupuis, J. C. (2019). Three-dimensional stochastic assimilation of gravity data in lalor volcanogenic massive sulphide, manitoba, canada. Canadian Journal of Earth Sciences, 56(5):556-568.

Uieda, L. (2018). Verde: Processing and gridding spatial data using Green's functions. Journal of Open Source Software, 3(30):957.

Uieda, L. and Barbosa, V. C. (2017). Fast nonlinear gravity inversion in spherical coordinates with application to the south american moho. Geophysical Journal International, 208(1):162-176.

Uieda, L. and Soler, S. (2020). Boule v0.2.0: Reference ellipsoids for geodesy geophysics, and coordinate calculations.

Uieda, L., Soler, S. R., Pesce, A., Oliveira Jr, V. C., and Shea, N. (2020). Harmonica: Forward modeling, inversion, and processing gravity and magnetic data.

Uwiduhaye, J. d., Mizunaga, H., and Saibi, H. (2018). Geophysical investigation using gravity data in Kinigi geothermal field, northwest Rwanda. Journal of African Earth Sciences, 139:184-192.

Verdun, J., Klingelé, E. E., Bayer, R., Cocard, M., Geiger, A., and Kahle, H.-G. (2003). The alpine Swiss-French airborne gravity survey. Geophysical Journal International, 152(1):8-19.

Verly, G. (1993). Sequential gaussian cosimulation: a simulation method integrating several types of information. In Geostatistics Troia'92, pages 543-554. Springer.

Wilmes, H., Wziontek, H., Falk, R., and Bonvalot, S. (2009). AGrav-the new international absolute gravity database of BGI and BKG and its benefit for the Global Geodynamics Project (GGP). Journal of Geodynamics, 48(3-5):305-309. 
Uncertainty analysis of gravity disturbance

Ziegler, P. (1990). Collision related intra-plate compression deformations in Western and Central Europe. Journal of Geodynamics, 11(4):357-388. 